\title{
THE ORAL AND WRITTEN LANGUAGE PROFICIENCY OF AN INDONESIAN BILINGUAL CHILD IN THE OHIO STATE, USA
}

\author{
Riana Permatasari \\ Ohio State University, \\ United States of America \\ Sultan Agung Islamic University, \\ Semarang, Indonesia \\ rianapermatasari0305@gmail.com
}

\begin{abstract}
This study was a qualitative case study conducted to investigate the oral and written language proficiency of an Indonesian bilingual child living in The Ohio State, USA. There were three research questions guiding this study as follows: (1) how the bilingual Indonesian child used the languages she spoke in oral and written forms?, (2) how was the child's oral proficiency for each language she spoke?, and (3) how was the child's written language proficiency for each language she spoke? The data in this study were gathered through analytical observation sheets, semi structured interviews, audio and video recording and transcriptions, and reading aloud and writing scoring. Then, the data were analyzed using inductive analysis such as doing field work to observe and recording the data, developing topics and categorizing the data into categories, refining and coding the data into more specific patterns to see the themes of the data, and seeking for narrative structures and visual representations. Based on the results of the study, there were three points concluded. First, my focal student and her community chose different languages to communicate based on the listeners' cultural background, age, and gender. Second, the Indonesian parents living there had an awareness of the importance of heritage language in spoken and written forms. Third, the student' oral and written language proficiency in English were higher than in Indonesian and Javanese. In conclusion, the student needed more space for developing her abilities in Indonesian and Javanese.
\end{abstract}

Keywords: bilingual, bilingualism, biliteracy, language proficiency

\section{INTRODUCTION}

Indonesia is a big country consisting of a lot of bilingual and multilingual people as most of its people speak two or more languages in their daily lives. Based on the survey conducted by the Department of Language Development in 2012, it has 546 languages spoken as a first language by its people. Most of Indonesian children acquire their ethnic language first and study the Indonesian language as the official language at elementary schools 
Permatasari, The Oral and Written Language Proficiency of An Indonesian...

(Nur, 2003). The Indonesian language functions to communicate with other people from across Indonesia because they speak different ethnic languages. Further, the children also study foreign languages such as English, French, Germany, etc. during their study in middle or high schools. Thus, there are three classifications of language among the Indonesian people as follows: (1) the national language (bahasa Indonesia/ Indonesian language), (2) the vernacular languages or ethnic languages, and (3) foreign languages (Nababan, 1982, cited in Nur, 2003). The Indonesian government placed a lot of importance on teaching these languages as indicated in the curriculum which the government demands schools to teach the vernacular languages as the local content subject, the Indonesian language and English as compulsory subjects. Thus, bilingual education in which the students are given opportunities to develop various languages during their study is highly supported by the educational system in that country.

In contrast, bilingualism and biliteracy is a debatable issue in the USA since bilingual students are often seen as students who have limited English proficiency (Oller's, 1982, cited in Baker, 2011) and there are language policies obstructing emergent bilingual students to develop their home languages such as English Only Policy, high stake testing policy, etc. which make bilingual students who are English Language Learners struggle in school more than any other groups of students (Gandara \& Hopkins, 2010). The groups of student who are struggling with the policies are including Spanish, African-American, Asian, and other students who do not speak English as their first language. Especially, for Indonesian children who are exposed into various languages, they will find difficulties in dealing with the different education system when they live in the USA.

There are some viewpoints of literacy of these minority students such as the skill approach, construction of meaning approach, and critical literacy approach. In the US the view points of the minority students tend to be the skill approach which assumes that literacy is the ability to encode symbols on a page into sounds followed by making meaning from those sounds (Baker, 2011). Further, the skill approach leads to teaching to standardized tests 


\section{EduLite}

Journal of English Education, Literature, and Culture

which can possibly decrease the importance of developing the higher order language and thinking. As a result, a great interest related to bilingualism and biliteracy has been growing in the US nowadays as many researchers have done a lot of research related to bilingualism and biliteracy to describe how bilingual students develop their language proficiency and how educational policies affect their language development.

The fact that the most of immigrant students including Indonesian children living in the US are struggling with the US government policies related to bilingualism and biliteracy became the point of consideration of conducting this study. This study was a qualitative case study which aimed at analyzing the oral and written language proficiency of an Indonesian bilingual child living in the US. There were three research questions guiding this study as follows: (1) how the bilingual Indonesian child used the languages she spoke in oral and written form?, (2) how was the child's oral proficiency for each language she spoke?, and (3) how was the child's writing proficiency for each language she spoke?

Bilingualism and biliteracy

Grosjean (2010, cited in Baker, 2011) defines bilinguals as people who use one or more languages in their daily communication. There are three views of bilingualism asserted by Baker including the monolingual view, semilingualism or double semilingualism, and holistic view of bilingualism. Based on the monolingual view, bilinguals are seen as two monolinguals in one person. For example, an Indonesian child may use Indonesian and English in his daily live, then his English competencies are often measured of a native monolingual English speaker. This fractional view is seen unfair by some educators because bilinguals use different languages with different people, so they may have stronger language abilities in each language but in different domains. In the contrary, semiliungualism views bilinguals tend to be dominant in one, some, or all languages they speak. This view gets a negative view as a language deficiency in bilinguals compared with monolinguals. Further, the holistic view of bilingualism proposes a new positive way in 
Permatasari, The Oral and Written Language Proficiency of An Indonesian...

regarding bilinguals as people who have multicompetencies in languages. Thus, a bilingual is an integrated whole who uses languages in different contexts, for different purposes, and with different people. As a result, one language competency may be stronger compared to the others because it depends on how often the language is used.

However, some educators regard bilinguals for being fully proficient in two languages. It is not aligned with the holistic view in which bilinguals will be more dominant in using and mastering one of the languages. The notion of bilinguals being fully proficient in two languages is categorized as a myth by Shin (2013). She also points out the other myths related to bilingual students such as bilingual immigrants are reluctant to learn English, children need early exposure to a second language if they want to learn it successfully and immigrant parents should speak the second language at home to help them succeed in schools, and high drop out of Hispanic students in the US demonstrate the failure of bilingual education. She argues that immigrant students are minority students who do not get enough chances to develop their language abilities in their first as well as the second language. For example, they have very limited access in home literacy in English etc. Moreover, the high rate level of drop out of Hispanic students is affected by the policy of high stake testing achievement in which they are assessed in English only, so Shin argues that it is unfair to judge them failed in bilingual education since they only assess in one language. As a result, the education system in the US should provide them more chances to take advantages of their first language to succeed in their schools.

The benefit of bilingualism and biliteracy

Many educators believe that bilingualism and biliteracy bring benefits towards education and students' lives even though some others see bilinguals have deficiencies in language competencies. Garcia (2009) suggests that there are two advantages for bilinguals. The first is cognitive advantages including metalinguistic awareness, divergent thinking, communicative sensitivity, and ability to learn multiple languages. Shin describes that the literature showing that bilingualism as an important factor in cognitive development is extensive. 


\section{EduLite}

Journal of English Education, Literature, and Culture

Bialystok (2004, cited in Garcia, 2009) the cognitive development of bilinguals is better than monolingual in which the bilinguals are able to make language structures more visible for them and organize their language system. Further, they incorporate them into communication. In addition, bilinguals understand two or more language systems as well as the cultures embedded inside them which enable them to think about an issue more flexible from different point of views based on the cultural background they have. They also have language choices that they apply to their communication. They may choose different languages according to the listeners. Thus, they have high communicative sensitivity as they are aware of the person they are talking to. Moreover, Hawkins (1986, cited in Garcia, 2009) has proposed a concept called language apprenticeship in which being bilinguals as the basis in acquiring other languages. People who are bilinguals will find easier in learning the other languages than monolinguals as they have higher metalinguistic awareness to make abstract concepts into more visible concepts for them.

The second is social advantages including socio-economic benefits, global and local interactions, potentializing of having 'acts of identities', and cultural awareness and construction. Bilinguals have broader opportunities to communicate with local people as well as foreigners as they can speak different languages and also know the cultural differences so they can communicate in global interactions more appropriately.

In short, even though the competencies of bilinguals in one language are higher than the other languages they speak, some educators see it as a language deficiency. Hoever, the most of educators also assert that bilingualism also bring the children benefits including cognitive and social benefits that help them involve in global communication.

\section{METHODS}

This study was designed as a case study because this study focused on an individual as the subject of the study to get a detailed analysis related to a particular research problem. In this case, this study investigated the oral and written language proficiency of an Indonesian bilingual child living in the US 
Permatasari, The Oral and Written Language Proficiency of An Indonesian...

in the languages she spoke. Thus, categorizing this study as a case study was aligned with the definition of a case study by Becker, (1970, cited in Fidel, 1984) in which he defined a case study as "a detailed analysis of an individual case supposing that one can properly acquire knowledge of the phenomenon from intensive exploration of a single case. Thus, a qualitative case study should be conducted through observations to record the data from an individual to be further analyzed in detailed and depth analysis to answer the research questions.

The data were gathered through multiple data sources including analytical observation sheets, semi structured interviews, audio and video recording and transcriptions, and reading aloud and writing scoring. The first data source was the analytical observations sheets which involved the process of recording observations reflectively and further getting the researcher to think about the elements or features of their meaning (Burns, 2010). Thus, it was not only a series of events, but also the reflections of the events. The observations were conducted during three months in various settings where the subject of the study dealt with such as the observation in the subject's house, in the neighborhood, and the school environment. The second was semi structured interviews which gave some flexibility according to how the interviewee responds (Burns, 2010). Thus, even though I had set a series of questions in advanced, but I also developed questions during the interviews to get richer information. The third was audio and video recording to observe how the subject interacted with the environments to see the semiotic details such as gestures, facial expressions, etc. The last was scoring for speaking and writing abilities in the languages she spoke. For speaking, the subject was assessed based on WIDA, SOLOM, holistic, and analytical rubric while the writing ability was assessed using holistic scoring rubric for writing, analytic scoring rubric for writing, and 6 points writer's rubric. Involving multiple data sources in this study was important to enable me get more comprehensive data.

This study followed four phases in conducting a case study according to McMillan and Schumacher (2001) as follows: (1) Phase 1, doing field work to observe and recording the data, (2) Phase 2, developing topics and categorizing 


\section{EduLite}

Journal of English Education, Literature, and Culture

Volume 1, Number 2, August 2016

the data into categories, (3) Phase 3, refining and coding the data into more specific patterns to see the themes or concepts of the data, and (4) Phase 4, seeking for narrative structures and visual representations. After making the narrative structures and visual representation, the conclusion was made for the whole investigation to answer the research questions.

\section{FINDINGS AND DISCUSSION}

The findings of the study were divided into four points including the description of contexts and learner, the description of bilingual oral language use, the description of bilingual written language use, the oral language proficiency of the student, and the written language proficiency of the student.

The description of contexts and learner

My focal student for this study was Dira (a pseudonym) who spoke Javanese, Indonesian, and English. She has been living in Columbus, Ohio, for five years. Columbus is the capital city of and the largest city in the state of Ohio. The city has a diverse economy based on education, government, insurance, banking, fashion, etc. Most of the population is white people. The following is the data related to the population in Columbus in 2012 .

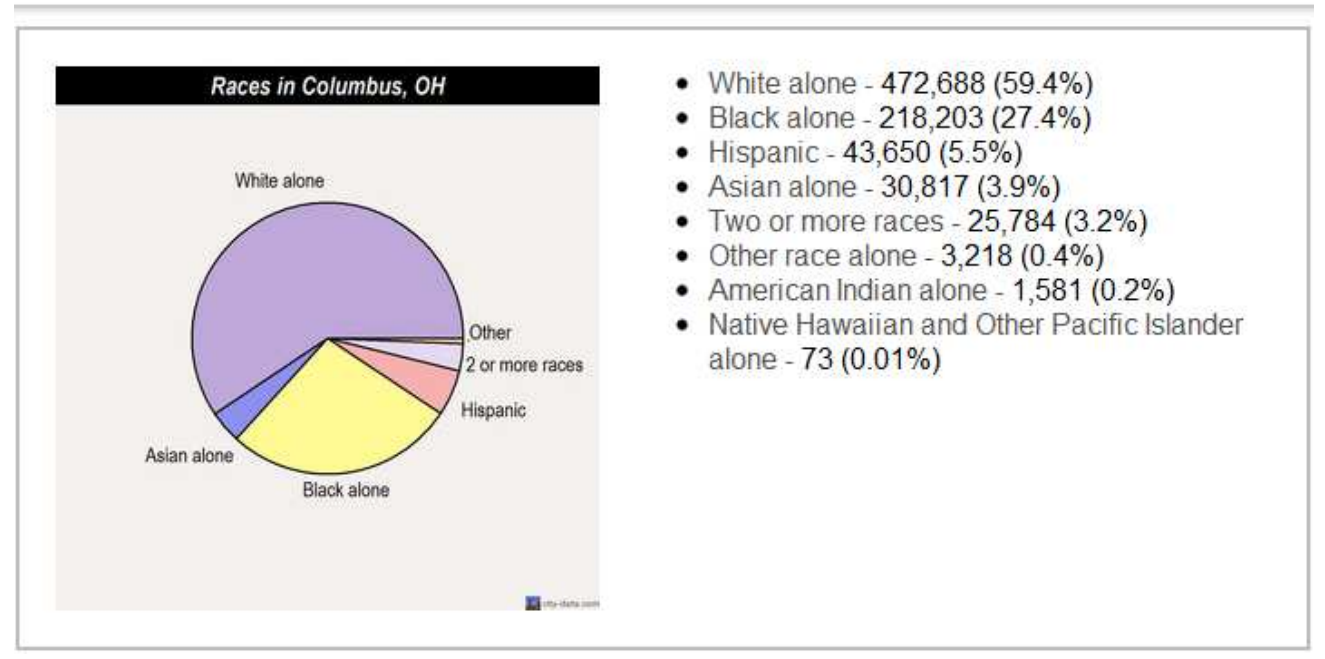

Figure 1. The Races Population in Columbus, Ohio (Columbus City Website) 
Permatasari, The Oral and Written Language Proficiency of An Indonesian...

Based on the data above, the city consists of various races even though the numbers are less comparing to the white people living in this city. It can be concluded that the city has diverse population with various background of economy, education level, etc. Regarding to the city population, in the residence where Dira and her family lived, there were a lot of people from many different countries who had various cultural, social, and economic backgrounds such as Chinese, Korean, African-American, Turkey, Arabic, Indonesian, Malay, etc. Dira and her family lived in Buckeye Village, the Ohio State University family housing.

Dira was accustomed to living in different provinces in Indonesia and different countries so that she was familiar with different cultures and languages. She was born in Solo, Central Java. Then, when she was six months after her birth, she went to Australia with her mother and Maria (a pseudonym, her elder sister) to accompany her father who was pursuing master's degree in Monash University at that time. She lived there for about a year and went back to Indonesia after her father finished his master's degree. Then, in 2010, she moved to Columbus, Ohio, USA, because her father was pursuing his doctoral degree at the Ohio State University. In short, she had been exposed to different languages and cultures since she was very young.

In addition, she also had an access to multicultural setting not only in her neighborhood but also in her school, where one third of students represented thirty countries. The multicultural activities received a lot of attentions in this school, such as International Night providing students and the school community with an opportunity to share cultures, traditions, arts and food from many different countries. Based on my interviews with my focal student, there was no prohibition for students to speak their languages while they were in class.

My focal student's class mostly consisted of students from India and the rest were from Italy, Africa, Asia, and South America. The students had rights to speak with their peers with similar native language at school as long as they were talking about the subjects being taught. However, my focal student rarely spoke Javanese and Indonesian at school because she did not have any partner to speak with even though there were some students from Indonesia 


\section{EduLite}

Journal of English Education, Literature, and Culture

Volume 1, Number 2, August 2016

in her school. However, they were younger than my focal student and they could not speak Indonesian because they had been living in Columbus since they were very young so they could not speak Indonesian. They were categorized as passive bilinguals while my focal student was an active bilingual (Baker, 2011). In conclusion, even though bilingualism and biliteracy were regarded in her school, my focal student was not able to develop her Javanese and Indonesian because she did not have any friends to speak with in her school. In short, she only had chances to use Indonesian and Javanese in her house and neighborhood.

The description of bilingual oral language use

There were four points I derived from my interactions with Dira and her family in various settings during my observations. The first was that this family was a multilingual family with one of the members was a passive bilingual. Dira was an infant bilingual since she had been developing Javanese and Indonesian since she was baby. Based on Baker (2011) infant or simultaneous bilingualism was when children learn two languages from birth. Then, when she was at first and second grade in elementary school in Surabaya, she was able to speak Mandarin, but now she was not able to speak Mandarin since she did not use it in her daily life. Based on the Iceberg Analogy or Common Underlying Proficiency in Baker (2011), Dira lost her ability in speaking Mandarin because her ability in speaking Mandarin was replaced by the languages which she usually used in her daily live. It was also related to what Baker (2011) called as language attrition in which English, Indonesian and Javanese were spoken mostly in her daily live which caused Mandarin was decreasing. This language attrition could be temporary or permanent. In addition, she had also been learning English since she was in the first grade of elementary school. Thus, she was a multilingual who was able to use Javanese, Indonesian, and English. Her dad, her mom, and her elder sister were also infant multilinguals but her younger sister only spoke English but she understood Indonesian and Javanese. Thus, based on her ability, her younger sister was categorized as a passive bilingual who was able to understand other languages but she could not bring it into conversation or 
Permatasari, The Oral and Written Language Proficiency of An Indonesian...

write in different languages (Baker, 2011). In short, this family was a multilingual family in which Dira, her mom, her dad, and her elder sister were productive bilinguals while her younger sister was a passive bilingual.

The second was that the length of exposure to three different languages affected their ability in using these three different languages. Her mom and her father who got more exposures in Javanese mostly tended to use Javanese in her daily life. However, her father seemed speaking English more than her mother since her father was an English lecturer so he was accustomed to speak English more than his wife. Dira and her elder sister were similar in using three different languages, they mostly spoke English since they got more exposure in English in the US, but they were still able to speak Indonesian and Javanese. On the other hand, the younger sister was only able to speak English since she had been living in Ohio since she was nine months after her birth so that she did not get enough exposure to Javanese and Indonesian as much as her sisters got.

The third was that there were the differences of language choice among the members of this family and the community. Based on my observation, Dira and her sisters tended to use English mostly in their daily lives. It was because now they were living in the US, and most of their friends spoke English. Thus, circumstances and situations were bases of their language choice. Comparing to her father and her mother, based on my observation, her father and her mother did not generalize their language choice, their language choices would depend on with whom they were talking, whether they had similar cultural background with the listeners. Similarly, the Indonesian community in Dira's resident used three different languages in their daily conversation based on the contexts. They would choose the appropriate language by considering the gender, status, age, and cultural background of the listener. Having language choice was one of the social benefits of being bilinguals based on Garcia (2009). These following were the examples of how they used oral language related to their listeners' gender, age, and cultural background.

Some examples related to the use of a certain language based on cultural background of the listeners: 


\section{EduLite}

Journal of English Education, Literature, and Culture

1. They used Javanese language if they were talking to Javanese people.

For example: Johan (a pseudonym, Dira's father) talked to me and other Javanese people using Javanese since we shared the same cultural background and Javanese was our native language so there would not create any problem when we used Javanese during our conversation.

2. They mixed Javanese and Indonesian if they were talking to Javanese and other people from other parts of Indonesia.

For example, Dia (a pseudonym, Dira's mother) did not only use Javanese but also Indonesian because she knew that one of my friends coming from Borneo Island in which they did not speak Javanese, so it would make my friend confused if she spoke Javanese only.

3. They spoke English to people from other countries

For example, Dira spoke English to her neighbor who was Korean since English was the only language that both of them understood each other.

4. They usually did translanguaging in their conversation since they knew that the people with whom they were talking understand the three languages.

Based on the examples above, the Indonesian people did translanguaging and chose different languages based on the cultural background of the listeners. It was related to pragmatics in which context would influence the communication. According to Diaz-Rico (2013: 38) pragmatics "includes three major communication skills". Those major skills are: (1) the ability to use language for different functions, (2) the ability to appropriately adapt or change language to the listeners or situations, and (3) the ability to follow the rules for conversations and narratives. From the examples above, there was a clear pattern that they used Javanese to talk with the people who shared the same cultural background, they spoke Indonesian to talk with the people who came from Indonesia but from different parts of Indonesia in which Javanese was not spoken, and they spoke English to talk with the people from different countries. In short, contexts really affect how communications were conducted among people. 
Permatasari, The Oral and Written Language Proficiency of An Indonesian...

The age also influenced the communication in this community. Javanese people used a certain word to address elder people to show their respect. These followings were the examples of the use of certain words to show respect for elder people.

- Dira addressed people who were elder than her parents using Pak Dhe (for men) and Bu Dhe (for women).

- Javanese people were accustomed to using Mba (for women) and Mas (for men) to address elder people, i.e. Dia (Dira's mother) addressed Retna by saying 'Mba Retna' to show her respect to her.

Based on the examples above, it was clear that there were some values, belief and norms in a certain language. The speakers of that language wanted to preserve these values, belief, and norms so they would use certain words to show that they still preserved these values. It was very difficult for Javanese people to address elder people using their names. Thus, when they talked using English to people from other countries, they addressed the names, but when they talked to Indonesian people, they used certain words to address elder people. In brief, the speakers wanted to preserve values, beliefs, and norms in a certain language.

The fourth was that her parents encouraged their children to keep their heritage language. As we know that heritage language was a big issue in the US because of the English Only Policy. Tse (2001: 30) states that "In fact, heritage languages vanish from immigrant families as children learn English and prefer it over the home language". In order to prevent the loss of heritage language, their parents kept doing translanguaging to their children and sometimes they spoke full in Javanese or Indonesian language to give their children access to their heritage language because they did not get any access to their heritage language in their schools since the majority of the students were English speakers.

In brief, related to the oral language use, the family and the community of my focal student tried to keep their language abilities in different languages by doing translanguaging. Moreover, they had different language choices based on the listeners which was aligned with the assertion of Diaz-Rico (2013: 19-40) that to speak appropriately, the speakers must take into 
account the gender, status, age, and cultural background of the listeners. It is because a communication always happens within a particular context and a language is always influenced by society and cultures. In addition, a language and cultures are intricately interwoven so it cannot be separated in communication.

The description of bilingual written language use

Based on my observations related to the bilingual written language use, in my focal student' house, I saw some books written in Indonesian. Moreover, some sticky notes in the house were written in Indonesian language. They also used the written form in Javanese and Indonesian in social media because they communicated with their friends and family in Indonesian using internet.

Similarly, in her community, they also read some books written in Indonesian language. Moreover, some parents also taught their children to write and read in Javanese and also Indonesian since they wanted their children were able to speak and write in three languages, but some others did not teach how to write in Javanese or Indonesian language as they regarded it can obstruct their children in acquiring English.

In short, the community still had awareness of the importance of written language use of their heritage and first language by providing books written in Indonesian and writing in Indonesian and Javanese to give their children an access to their language heritage.

The oral language proficiency of the student

My focal student's oral proficiency was analyzed based on the process and the data gathered when she was reading a loud a passage in Indonesian and English with the same story and genre. She was not assessed in speaking because it was difficult to assess her oral language proficiency in speaking for she did much translanguaging as she knew I also understood the three languages she spoke. The titled of the story was Malin Kundang, one of Indonesian folklores. The genre of the story was narrative. The story was chosen by her since she said to me that she liked the story as her father told this story before she slept. 
Permatasari, The Oral and Written Language Proficiency of An Indonesian...

There was a significant difference when my focal student was reading Malin Kundang in English and Indonesian. When she was reading the Indonesian version, she made some mispronunciations and did not sound fluent since she made a lot of pauses and repetitions of words that she did not know such as bersikeras (perseverence), di lengannya (in his arms), membesarkan (raise), merantau (wandering), etc. In contrast, when she read the story in English, she sounded very fluent and did not have any significant obstacles when she was reading it.

The next was the product of her reading or the data were assessed using four different rubrics to draw the general pattern of the data. The rubrics employed to assess student's oral proficiency were WIDA, SOLOM, holistic scoring rubric for speaking, and analytic scoring rubric for speaking. The following was the result from those rubrics for Indonesian and English.

\begin{tabular}{|c|c|c|c|c|}
\hline Language & WIDA & SOLOM & $\begin{array}{c}\text { Holistic scoring } \\
\text { rubric }\end{array}$ & $\begin{array}{c}\text { Analytic scoring } \\
\text { rubric }\end{array}$ \\
\hline English & $\begin{array}{l}\text { Based on } \\
\text { WIDA rubric, } \\
\text { my focal } \\
\text { student } \\
\text { belonged to } \\
\text { developing } \\
\text { level. }\end{array}$ & $\begin{array}{l}\text { Comprehension }= \\
4 \\
\text { Fluency }=5 \\
\text { Vocabulary }=4 \\
\text { Pronunciation }= \\
4 \\
\text { Grammar }=4\end{array}$ & $\begin{array}{l}\text { Based on holistic } \\
\text { rubric, my focal } \\
\text { student' oral } \\
\text { proficiency } \\
\text { belonged to level } \\
5 \text {. }\end{array}$ & $\begin{array}{l}\text { Speaking }=5 \\
\text { Fluency }=\text { level } 5 \\
\text { Structure }=4 \\
\text { Vocabulary }=5 \\
\text { Listening }=5\end{array}$ \\
\hline Indor & $\begin{array}{l}\text { Based on } \\
\text { WIDA rubric, } \\
\text { my focal } \\
\text { student } \\
\text { belonged to } \\
\text { developing } \\
\text { level. }\end{array}$ & $\begin{array}{l}\text { Comprehension }= \\
3 \\
\text { Fluency }=3 \\
\text { Vocabulary }=4 \\
\text { Pronunciation }= \\
3 \\
\text { Grammar }=3\end{array}$ & $\begin{array}{l}\text { Based on holistic } \\
\text { rubric, my focal } \\
\text { student' oral } \\
\text { proficiency } \\
\text { belongs to level } \\
3 .\end{array}$ & $\begin{array}{l}\text { Speaking }=3 \\
\text { Fluency }=3 \\
\text { Structure }=3 \\
\text { Vocabulary }=4 \\
\text { Listening }=5\end{array}$ \\
\hline
\end{tabular}

Table 1. The results of assessment of the student's oral language proficiency

From the table 1, we could see that the results indicated that the student's English oral proficiency was higher than the Indonesian. Compared to her proficiency in English and Indonesian, her oral proficiency in Javanese was quite low and belonged to beginner so that I could not use the rubrics to assess her oral proficiency in Javanese. Instead of giving a passage in Javanese to read, I decided to write some Javanese sentences in ancient Javanese symbols to her. I started with the simple sentence then gradually developed the difficulties. She could read the basic symbols of Javanese and 


\section{EduLite}

Journal of English Education, Literature, and Culture

Volume 1, Number 2, August 2016

three of five sentences I wrote for her. However, she does not find any significant difficulty in reading Javanese in alphabetic symbol comparing to ancient symbol of Javanese.

In short, her oral language proficiency in English is the highest compared to Indonesian and Javanese.

The written language proficiency of the student

The student's written language proficiency was analyzed based on the process and the written product of the student. After reading the story and asking her preference in which language she felt comfortable with during reading process, the student was asked to rewrite the story in Indonesian and English. There was also a significant difference when my focal student was rewriting Malin Kundang in English and Indonesian based on her understanding and using her own sentences. When she was writing the English version, she did it quickly and did not show that she found difficulties in writing the story. In contrast, when she was writing the Indonesian version, she looked at the English version she had made and then translated into Indonesian and she also asked me some vocabularies since she was not sure whether she picked correct word or not but I told her that it was not a test, so it would be ok if she did not know the words. Because she translated the English version into Indonesian version, she made some grammatical mistakes in Indonesian as the rules in Indonesian and English were different. The written products of my focal student were analyzed using a proficiency holistic scoring rubric for writing, analytic scoring rubric for writing, and 6 points writer's rubric. The following is the results from those rubrics for Indonesian and English.

\begin{tabular}{cccc}
\hline Language & $\begin{array}{c}\text { Holistic scoring } \\
\text { rubric }\end{array}$ & $\begin{array}{c}\text { Analytic scoring } \\
\text { rubric }\end{array}$ & 6 points writer's rubric \\
\hline English & Level 5 & 3 reasonable control & Capable \\
\hline Indonesian & Level 4 & 3 reasonable control & Developing \\
\hline
\end{tabular}

Table 2. The results of assessment of the student's written language proficiency 
Permatasari, The Oral and Written Language Proficiency of An Indonesian...

From the table above we could see the results from two rubrics have differences between English and Indonesian, while in analytic scoring rubric my focal student got the same level. It was because in analytic scoring rubric if the student had significant punctuation errors, the written proficiency was in level 3 while in level 4 there was no punctuation errors. In fact, my student made punctuation error in both languages. In brief, the results of my focal student writing in Indonesian and English were almost similar. Another result in her writing was she mixed the conversational and academic language in Indonesian so she picked inappropriate words in her writing. Compared to Indonesian and English, her Javanese writing was quite lack because she only could write her name in ancient symbols of Javanese so she could be categorized as beginner in using ancient symbol of Javanese.

In short, based on the data, my focal student had higher level of written language proficiency in English than in Indonesian and Javanese.

\section{Discussion}

Based on the results of the study, there are three points derived in this study. The first, her oral and written language proficiency in English was higher than Javanese and Indonesian because she was mostly exposed in using English in her daily life instead of Indonesian and Javanese. At school, she did not have any friend to speak in Indonesian and Javanese. She only used Javanese and Indonesian in her neighborhood and home in not a significant exposure. It was also related to what Baker (2011) called as language attrition. The language attrition can put the heritage languages at risks.

The second, there was a transfer of English and Indonesian in her writing and speaking. There are two perspective of the transfer in bilingualism and biliteracy called fractional and holistic view. The fractional view argues that bilinguals as "being like two monolinguals in one person" while holistic view asserts that "each bilingual is a unique individual who integrates knowledge from both language from both languages to create something more than two separate languages" (Grosjean, 1982 cited in Reyes, 2012). The holistic view gives us the answer of why English and Indonesian transfer in 


\section{EduLite}

Journal of English Education, Literature, and Culture

her writing. We can find the transfer from Indonesian in her English writing and vice versa because being bilingual did not mean that my focal student had completely two different separate languages which we could shut off or on one of the language systems that she knew.

The third, her conversational language was more developed than the academic language. Cummins (1979, 1994, 2000) cited in Aukerman (2007: 626) argues that "children typically develop informal "playground" talk or basic interpersonal communication skills (BICS) sooner and more easily than they have developed skills to cope with the cognitively demanding language they are expected to understand and use to complete academic tasks - what he terms cognitive language proficiency (CALP). Moreover, Freeman and Freeman (2004) and Peregoy, Boyle, and Cadiero-Kaplan (2013)also point out that children find it more difficult to develop academic languages instead of conversational language because academic language is used exclusively in school settings, has less contextual supports, and greater cognitive demands.

My focal student did not find any significant difficulties when she used Indonesian and Javanese in speaking even though she had been exposed in speaking country for years. However, she had lack of academic language used in Indonesian school contexts which might create obstacles for her during her study in Indonesia after going back from Columbus, Ohio. Thus, she needed many exposures to academic language in Indonesian. Her parents might provide her with non-fiction books written in Indonesian so my focal student was able to differentiate the conversational and academic language. Her teachers in Indonesia should allow her in using English to help her in learning and translating the context that she did not understand. In addition, her teachers might also use cognates to help her develop her academic language.

\section{CONCLUSIONS}

There are three points concluded in this research as follows: (1) my focal student and her community tended to choose different languages in oral communication based on the listeners' cultural background, age, and gender, (2) there was an awareness of the importance of their heritage language in oral 
Permatasari, The Oral and Written Language Proficiency of An Indonesian...

and written form so the parents provided the children books written in Indonesian and spoke in their heritage languages, and (3) the student's oral and written language proficiency in English were higher than in Indonesian and Javanese as she got more exposures in using English instead of Indonesian and Javanese. In conclusion, emergent bilingual students need space for developing their home languages to help them succeed in educational setting. Teachers should be aware of their abilities in two or more languages and make them useful for supporting the success of the students. Even though sometimes teachers face dilemma because of policies not aligned with their beliefs, their pedagogies can help emergent bilingual students to develop their languages and succeed in academic setting.

\section{REFERENCES}

Aukerman, M. (2007). A culpable CALP: Rethinking the conversational/ academic language proficiency distinction in early literacy instruction. The Reading Teacher, 60 (7), 626-635.

Baker, C. (2011). Foundations of bilingual education and bilingualism (5th ed). Bristol: Multilingual Matters.

Burns, A. (2010). Doing action research in English language teaching: A guide for practitioners. New York: Routledge.

Columbus City Official Website. http://www.city-data.com/city/ColumbusOhio.html

Diaz-Rico, L. (2013) The crosscultural, language, and academic development handbook: A complete $K-12$ reference guide (5th ed). New York: Pearson.

Fidel, R. (1984). The case study method: A case study. LISR, 6, 273-288.

Freeman, D. \& Freeman, Y. (2004). Essential linguistics: What you need to know to teach reading, ESL, spelling, phonics, grammar. Portsmouth, $\mathrm{NH}$ : Heinemann.

Gandara. P. \& Hopkins. M. (2010). Forbidden language: English restrictive language policies. New York: Teachers College Press Columbia University.

Garcia, O. (2009). Bilingual education in the 21st century: A global perspective. Malden, MA: Wiley-Blackwell. 
McMillan. J. H., \& Schumacher, S. (2001). Research in education: A conceptual introduction (5tg ed). New York: Longman.

Nur, C. (2003). English language teaching in Indonesia: Changing policies and practical constraints. In H. W. Kam \& R. Y. L. Wong (Eds.), English language teaching in East Asia today: Changing policies and practices. Singapore: Times Media Private Limited.

Peregoy, S. F., Boyle, O., \& Cadiero-Kaplan, K. (2013). Reading, writing, learning in ESL: A resource book for teaching K-12 English learner (6th ed.). Boston: Pearson.

Reyes, I. (2006). Exploring connections between emergent biliteracy and bilingualism. Journal of Early Childhood Literacy, 6 (3), 263-292.

Shin, S. J. (2013). Bilingualism in schools and society: Language, identity, and policy. New York: Routledge.

Tse. (2001). "Why don't they learn English?" Separating fact from fallacy in the U.S language debate. New York: Teacher's College Press. 